\title{
CONSUMER AWARENESS AND KNOWLEDGE ABOUT FOOD SOURCES AND POSSIBLE ENVIRONMENTAL IMPACT
}

\author{
S. WUNDERLICH \& M. SMOLLER \\ Department of Nutrition and Food Studies, Montclair State University, United States of America.
}

\begin{abstract}
This study investigates consumer awareness and knowledge about two methods of food production and possible environmental impact, specifically organic farming and genetically modified or engineered food production. Consumers are often unaware of the details of the first step of the food supply chain, which is the food production method and its environmental impact. It is believed that organic farming causes the least damage to the environment as it uses no pesticides or herbicides in agriculture. However, genetically modified food is used frequently in the United Sates to increase yield and to meet the growing demand for food. Consumers generally are becoming more interested to learn about the food they purchase and the possible environmental impact of how it was produced. An online survey was conducted to evaluate consumers' knowledge about the production systems and their preferences. Two hundred and four adult participants answered all the questions on the survey. The survey questions included demographic data and general questions about their knowledge of and their beliefs regarding different food production systems, particularly the genetically modified food and potential environmental impact. Almost half (48\%) of the participants believed that genetically modified food production has a harmful impact on the environment, while $31.4 \%$ had no knowledge about this method of food production and possible environmental impact. A $\chi^{2}$ test showed a significant association between preference for non-genetically modified food and individuals' beliefs on how this food production system may impact the environment $\left(\chi^{2}(1)=29.592, p=0.001\right)$. Seventy-five percent, of the 98 participants who believed that genetically modified food production has a harmful impact on the environment, preferred foods to be labeled. A majority (almost 80\%) of participants acknowledged that their food purchasing decisions are contingent on the method of food production and its possible impact on the environment. Keywords:consumer preference, education, environment, genetically modified organism (GMO), Green Food Supply Chain (GFSC), labeling, organic, purchasing decisions, sustainability.
\end{abstract}

\section{INTRODUCTION}

Attention to the issues of environmental protection, sustainability and food security is becoming increasingly essential as the world's population increases. Solving these issues will require continuous improvement in the methods of food production. At the same time, consumers are becoming more interested in learning about the sources of their food and if the methods of food production have potential negative impact on the environment. Therefore, food production systems are moving more toward ecologically friendly processes that produce higher product yields. Concurrently, consumers are becoming concerned and mindful with how different food production systems may impact the environment as food products move through the food supply chain [1].

The recent movement, in the United States of America, toward the environmentally friendly and sustainable agriculture practices is the Green Food Supply Chain (GFSC) concept. This approach includes a concept that takes the environmental impact of food production into consideration. This method encourages food companies to minimize food waste and reduce pollution during all phases of the supply chain, including food production, transportation and delivery to consumers [2]. Consumers' food choices and preference are influenced by many factors such as nutritional quality, taste and cost, and most recently, consumers are becoming 
progressively more apprehensive and interested in how their food is sourced and produced and whether it is ecologically responsible [3].

Since consumer demand drives food production, consumer awareness and knowledge about food production practices and their potential impact on the environment are critical to study.

\subsection{Environmentally sustainable agricultural practices}

The food supply chain is a dynamic supply and demand that ultimately moves food products from farms to consumers. It involves a network of producers, distributors, manufacturers, retailers, governments and consumers. The GFSC emerged as one that incorporates environmentally sustainable practices into production. Some examples of environmentally conscious agricultural practices include reducing the amount of pesticides used during farming in order to promote biodiversity, decreasing water usage, preventing soil erosion and treating livestock ethically [4]. This model is also practiced in organic farming that does not use chemicals in its agricultural practices. Also, some companies are using the GFSC model with success and innovation. For example, one company replenishes water in water-insecure communities in order to offset the 305 billion liters of water used per year in the production of its products [5]. During the transportation process, some manufactures may choose to shorten shipments to reduce $\mathrm{CO} 2$ emissions while shipping products. From a retailing standpoint, using recyclable packaging for products is more sustainable and it is a commonly used practice [4]. Finally, consumers may participate in the GFSC by choosing the products that have been produced in environmentally mindful ways. Of course, consumers must seek information and be knowledgeable about how their food was produced and moved within the food supply chain.

As the world population grows, those who are participating in the food supply chain should be informed how to balance the need for increased food production with sustainable practices [4]. According to the Food and Agricultural Organization, if global food production does not expand by at least $60 \%$ within the next 30 years, then the world may face a global food shortage [4]. It has become necessary for all the players within the food supply chain to collaborate together in order to produce food that satisfies these ever-changing world population needs and at the same time protect the environment [4].

\subsection{Agricultural methods in the United States}

Currently, there are three main food production systems in the United States. They include organic and conventional farming and the use of genetically modified organisms (GMO) or engineered food (GM). This study focuses on GMOs within the food supply chain and the consumers' preferences and purchasing choices when they learn that the food is produced by a genetically modified method. GMO refers to food products where genes have been altered by biotechnology in order to express certain favorable characteristics in the plants. Scientists introduce genetic sequences into organisms in order to enhance farming techniques and to produce more attractive products with better yields. Many GM foods are bred to be resistant to pests and disease, to be more tolerable to pesticides, to improve nutritional value and to prolong shelf life [6]. Scientists began manipulating genes and genetically modifying crops in the 1980s, and the first GM crop became available to the public in 1994 [7]. For the first time, the public was exposed to a GM tomato whose genetic sequence was altered to prolong and enhance its ripeness. GM foods eventually became commercially popular in the 
American food supply by 2006; however, there were no specific information such as labeling policies or rules in effect at the time to let consumers know about the method of food production. By 2013, the United States became the world's largest producer of GM crops, with over $94 \%$ of its soybeans and $90 \%$ of its corn undergoing genetic modification [7]. Although GM food production has become widely utilized, there is some debate regarding its safety and about its impact on the environment. For this reason, consumers began demanding that food manufacturers disclose GM ingredients on their packaging. Currently, the Food and Drug Administration (FDA) allows manufacturers to voluntarily choose whether or not they wish to disclose if their products contain GM ingredients. The only entity in the United States that currently labels non-GMO foods is the Non-GMO Project, which began labeling foods in 2010 [8]. The non-GMO Project is a non-profit organization that verifies that a product contains less than $0.9 \%$ of GMO ingredients with a 'Non-GMO Verified' label. The voluntary declaration of GM ingredients is about to change after a new national GMO-labeling law was signed in July 2016 [9]. This new law mandates that all GM foods must disclose their GM ingredients to consumers. GM ingredients will be disclosed via an electronic code, text or symbol that will be displayed on food packages. More specific rules and standards regarding this law will be set by the United States Department of Agriculture (USDA) within the next two years [9].

According to the USDA, organic foods must meet the following requirements: (1) must be produced without the use of genetic engineering, ionizing radiation or sewage sludge; (2) must be produced with only substances from a list of approved Allowed Substances; and (3) production must be overseen by a USDA National Organic Program-authorized certifying agent while following all of the USDA's regulations [10]. Foods produced through non-organic methods, also known as conventional foods, often contain GMOs. Conventional farming is the oldest and most traditional production method. However, modern technology has created significant crossover between conventional and GM production [11].

\subsection{Consumer knowledge and preference toward different food production systems}

There are several factors that influence consumer attitudes and preference toward different food production systems including GM foods. Consumers may or may not choose these foods based on their personal morals and ethics and how society views and media portrays market foods to the consumer. Other factors that may affect the acceptability of GM foods include how the product is perceived regarding its safety and environmental impact during production or transport. Consumers' attitude toward technology, policies and their education and income level and price are also important aspects in their purchasing decision [3]. Consumers' overall concern for the world appears to be linked to sustainable and organic food production methods that may work to preserve the world's environment while yielding high food production. A study from the Journal of Law, Medicine, \& Ethics examined the extent to which consumers associate health, safety and the environment with certain food labels [12]. The study asked 185 participants from the California Western School of Law community to rate how healthy, safe or environmentally friendly GMO foods are compared to other food products. On average, participants consistently rated GMO foods 1.1-1.8 points lower on a five-point scale than organic or non-GMO foods. The study ultimately revealed that participants favored food labels that appear more natural over foods containing GM ingredients, despite the fact that the FDA does not promote the idea that GMOs are not safe for consumption [12]. 
A study from the University of Latvia assessed 1,184 participants' knowledge, attitudes and beliefs toward GMOs using a ten-point Likert scale [13]. The study revealed that consumers were very skeptical of GM animal products, with an average acceptance of 1.97. Participants evaluated the benefits of GMOs as low (average value of 3 or less) but expressed that they would be more accepting of GMOs if they were more environmentally friendly. Participants also expressed concern over GMOs' safety, with the majority of participants believing that GMOs are not safe for the environment, for animals or for humans. Participants also agreed (average 6.89) that GMOs are simply unnatural, something they view negatively. Despite the participants' strong, negative perceptions of GMOs, half of the participants rated their knowledge of GMOs less than 5, while $16.4 \%$ of participants ranked their knowledge at 3 [13]. A study that surveyed 346 nursing students' attitudes toward GMOs revealed that $77.7 \%$ believed GMOs are dangerous to living things, and $72.8 \%$ thought that GMOs are not safe for consumption [14]. However, $82.9 \%$ strongly believed that society is not well informed regarding the risks and benefits of GMOs [14].

A study conducted at a public university in New Jersey also confirms that there is a lack of knowledge surrounding the word 'non-GMO'. More than half (54\%) of the 491 participants who completed an online survey assessing their knowledge, attitudes and beliefs regarding GM foods admitted to knowing little to nothing about GM foods, while $25 \%$ stated that they have never heard of GMOs. Despite this lack of awareness, $73 \%$ of respondents believed that the labeling of GM foods should be mandatory, and only $8 \%$ thought that GM foods were safe to eat [7]. However, according to a study that surveyed 331 people in northern New Jersey about their knowledge and attitudes toward GM food production, attitudes toward GMs were strongly correlated with overall knowledge $(r=0.701)$. This study revealed that the stronger a consumer's knowledge about GM food production was, the more positively they viewed non-GM foods $(r=0.413)$ [3]. These studies suggest that consumers have negative perceptions regarding GMOs due to a gap in knowledge.

The public opinion about GM foods is highly divided due to receiving conflicting and not scientifically proven messages from multiple sources of information. The misconceptions surrounding GMOs are likely due to consumers not knowing where to look for reliable information and due to the fact that information regarding GM foods is still evolving [3]. A study from the Journal of Review of Policy Research conducted focus groups to better understand consumer attitudes toward the use of nanotechnology in food production [15]. Several focus groups conducted in Minnesota and North Carolina evaluated 56 participants' knowledge, attitudes and beliefs toward 'nano-foods'. The findings from the focus groups revealed a general consensus that foods produced with nanotechnology should be labeled appropriately. However, participants expressed concerns that if foods possessed a label indicating a food was made with nanotechnology, consumers may not know what that necessarily means: 'Putting that (label) "made with nanotechnology" isn't going to mean anything to anyone, unless they know what nanotechnology is' [15]. This study shows that there is a great deal of uncertainty regarding the knowledge of GM foods and foods produced with technology. A systematic review asserts that consumer knowledge of GMOs is generally low, which leads to misunderstandings about their health benefits and safety. The authors attribute this gap in knowledge to the fact that consumers typically get their information about GMOs from incomplete sources such as the media and the Internet [16]. The study that assessed Latvian nursing students' attitudes toward GMOs revealed that $21.7 \%$ of participants get their information about GMOs from the Internet, $74.3 \%$ from the television or radio, 27.7\% from the newspaper and $22.3 \%$ from a friend [14]. The ultimate consensus that may be made is that 
despite a lack of consumer knowledge regarding the term GMO, consumers tend to have negative attitudes and perceptions toward GM products.

\subsection{The possible environmental impact}

The impact that GMOs have on the environment is not completely understood and confirmed, and it is a controversial issue, as there are pros and cons of GMO food production. The environmental impact of GMO production is ambiguous, as there is currently no consensus on what is considered 'environmental damage' in regard to GMO food production [17]. There is currently a delicate balance between feeding the growing world population while producing food in environmentally conscious ways. Research shows that GMO crops are resistant to pests and disease, allowing for more efficient production and abundant crop yields. This efficient production utilizes less land and resources, minimizing these aspects of potential environmental impact [18]. In contrast, organic food production is believed to cause less environmental damage per square mile cultivated. However, organic farming may have a negative overall impact on the environment as it utilizes more land and resources during production [19]. Opponents to GMOs argue that GMO production compromises biodiversity as GM crops transmit traits to native species. This ultimately leads to a decline in genetic diversity, something that is crucial to the survival of certain wild variety crops [18]. A recent review of the environmental impact of GMOs asserts that there is insufficient evidence to explicitly classify GMOs as either strictly harmful or beneficial to the environment. The review addresses both the issues and advantages of GMO production, while acknowledging that further research in this area is needed [20]. The evaluation of the environmental safety of GM food production is challenging due to this uncertainty. Assessing the environmental impact of GM crops ultimately requires further research and longitudinal studies by scientists and farmers.

The purpose of this paper is to focus on the food production and consumer pieces of the food supply chain and if there is a known environmental impact. Furthermore, this study is to assess consumer knowledge, attitudes and beliefs regarding food production system, particularly GM food and its relation to the environment.

\section{MATERIALS AND METHODS}

Online surveys were administered using an online plea to the community at the second largest public university in New Jersey, USA. Inclusion criteria and to be eligible to participate in this study were age, needed to be 18 years or older, live in the United States and routinely purchase foods at supermarkets in the United States. The 15-20-minute survey assessed knowledge and perception of two agricultural methods, namely, genetically modified foods and organic foods. The institutional review board of the university approved the protocol for the study.

Participants were first asked whether or not they have heard of the term non-GMO before and were then prompted to provide their own definition of the term. Subsequent questions included prompts about their purchasing behaviors and beliefs regarding these products. Participants were asked how often they notice and look for non-GMO food labels in the grocery store (all the time, sometimes or never) and if they prefer to purchase products with a nonGMO label (yes or no). Participants were then asked, 'the following statement BEST reflects my beliefs regarding the impact of producing GMO foods on the environment'. Participants were able to choose from the following options: (A) I believe that producing GMO foods has 
a harmful effect on the environment, (B) I believe that producing GMO foods has a beneficial effect on the environment, (C) I believe that producing GMO foods has no effect on the environment or (D) I do not know how producing GMO foods affects the environment. Demographic questions regarding age, ethnicity, gender, income, education level and location were also included to stimulate more context and qualitative data (Table 1).

The Statistical Package for the Social Sciences (SPSS) 22.0 (Armonk, NY: IBM Corp) and Microsoft Excel were used to analyze the data. Chi-squared tests were used to assess the

Table 1: Demographic characteristics $(n=204)$.

\begin{tabular}{|c|c|c|}
\hline Category & $\mathrm{n}$ & $\%$ \\
\hline \multicolumn{3}{|l|}{ Gender } \\
\hline Male & 33 & 16.2 \\
\hline Female & 170 & 83.7 \\
\hline No response & 1 & 0.5 \\
\hline \multicolumn{3}{|l|}{ Age (years) } \\
\hline Mean $( \pm \mathrm{SD})$ & $25.9(+8.4)$ & \\
\hline Range & $46(18-64)$ & \\
\hline \multicolumn{3}{|l|}{ Ethnicity (may identify as multiple) } \\
\hline White, non-Hispanic & 148 & 72.5 \\
\hline Asian & 13 & 6.4 \\
\hline Hispanic or Latino & 35 & 17.2 \\
\hline Black of African-American, non-Hispanic & 10 & 4.9 \\
\hline Other & 2 & 1.0 \\
\hline No response & 1 & 0.5 \\
\hline \multicolumn{3}{|l|}{ Income } \\
\hline$\$ 0-\$ 25,000$ & 48 & 23.5 \\
\hline$\$ 25,001-\$ 50,000$ & 35 & 17.2 \\
\hline$\$ 50,001-\$ 75,000$ & 28 & 13.7 \\
\hline$\$ 75,001-\$ 100,000$ & 24 & 11.8 \\
\hline$\$ 100,001+$ & 34 & 16.7 \\
\hline No response & 35 & 17.2 \\
\hline \multicolumn{3}{|l|}{ Education } \\
\hline High school diploma & 49 & 24.0 \\
\hline Associate degree & 25 & 12.3 \\
\hline Bachelor's degree & 87 & 42.6 \\
\hline Master's degree & 37 & 18.1 \\
\hline Doctoral degree & 3 & 1.5 \\
\hline No response & v3 & 1.5 \\
\hline
\end{tabular}


association between preference for non-GMO labels and one's beliefs regarding how GMO production impacts the environment.

\section{RESULTS}

The original sample size was 214 individuals who answered part of the survey questions. However, 204 participants completed all the questions in the survey and their data were included in the study and analyzed. Ten participants were eliminated from the study due to incomplete survey responses. The participants were mostly female $(83.7 \%)$ and white $(72.5 \%)$, with ages ranging from 18 to 64 years of age (mean $=25.9 \pm 8.4 \mathrm{SD}$ ). More than half $(54.4 \%)$ of participants earn $\$ 50,000 /$ year or less, and $78.9 \%$ of participants hold a bachelor's degree or lower. The majority $(92.2 \%)$ of participants resided in New Jersey, while the rest were from Pennsylvania, Delaware, Virginia, New York and Georgia.

It is important to evaluate the general awareness of participants about the different agricultural methods such as GM food production system. Table 2 represents awareness of participants regarding the food production methods. A great majority, 98.5\%, of participants had only heard of the term 'GMO', while $7.8 \%$ of the sample admitted to not knowing what the term means.

The questions on the possible environmental impact revealed that about half (48\%) of the participants believed that GMO food production has a harmful impact on the environment. There were $31.4 \%$ of participants who did not know how GMO food production affects the environment (see Table 3). A chi-squared test showed a statistically significant association between preference for non-GMO labels and an individuals' beliefs on how producing GMOs impacts the environment $(\chi 2(1)=29.592, p=0.001)$. Of the 98 participants that believed that producing GMO foods has a harmful impact on the environment, $75 \%$ preferred foods with a non-GMO label to foods without a non-GMO label. Of the 64 participants who stated that they did not know how GMO food production impacts the environment, $51 \%$ do not prefer food items with a non-GMO label. The majority of participants (79.4\%) stated that the impact a particular food had on the environment affects their food purchasing decisions all of the time or sometimes (see Table 4).

\section{DISCUSSION}

There is still uncertainty regarding the different methods of food production in the United States and their possible effects on the environment. Consumers are not educated enough about the agricultural methods of food production and sources of food they consume. This study,

Table 2: Awareness of food production methods $(n=204)$.

\begin{tabular}{llll}
\hline \multicolumn{4}{c}{ Awareness of production methods } \\
\hline $\begin{array}{l}\text { I have heard of the term ... } \\
\text { 'Genetically modified food' }\end{array}$ & Yes & No & No response \\
$(\mathrm{GMO})$ & $201(98.5 \%)$ & $3(1.5 \%)$ & $0(0.00 \%)$ \\
& I do not know & $\begin{array}{l}\text { Able to provide } \\
\text { explanation }\end{array}$ & No response \\
$\begin{array}{l}\text { Explanation of what GMO } \\
\text { means }\end{array}$ & $16(7.8 \%)$ & $186(91.2 \%)$ & $2(1.0 \%)$ \\
\hline
\end{tabular}


Table 3: Environmental beliefs for non-GMO foods $(n=204)$.

\begin{tabular}{lrrr}
\hline Statement & $\boldsymbol{n}$ & $\%$ \\
\hline The following statement best reflects my beliefs regarding the impact of & & \\
producing GMO foods on the environment: & & \\
I believe that producing GMO foods has a harmful effect on the environment & 98 & 48.0 \\
I believe that producing GMO foods has a beneficial effect on the environment & 17 & 8.3 \\
I believe that producing GMO foods has no effect on the environment & 7 & 3.4 \\
I do not know how producing GMO foods affects the environment & 64 & 31.4 \\
No answer & 18 & 8.8 \\
\hline
\end{tabular}

Table 4: Environment and impact on purchasing decisions $(n=204)$.

\begin{tabular}{lrlll}
\hline Statement & All of the time & Sometimes & Never & Missing \\
$\begin{array}{l}\text { The impact of producing a } \\
\text { certain food item on the } \\
\text { environment affects my food } \\
\text { purchasing decisions }\end{array}$ & $24(11.8 \%)$ & $138(67.6 \%)$ & $24(11.8 \%)$ & $18(8.8 \%)$ \\
$\begin{array}{l}\text { My belief about how produc- } \\
\text { ing GMO foods impacts the } \\
\text { environment influences my } \\
\text { food purchasing decisions }\end{array}$ & $32(15.7 \%)$ & $86(42.2 \%)$ & $57(27.9 \%)$ & $29(14.2 \%)$ \\
\hline
\end{tabular}

although a small sample size, has revealed that despite the ambiguity surrounding GMOs and the impact that their production may have on the environment, consumers perceive GMOs as harmful to the environment. Although most of the participants (almost 90\%) had heard the term GMO, which may be due to the demographic of this population who were college educated, the majority either does not know how GMO food production impacts the environment $(31.4 \%)$ or believe that it does have a harmful effect on the environment (48.0\%). There is clearly some familiarity with the term GMO and GMO labels among participants, as nearly all have heard of the term before. The results also suggest that consumers are being exposed to more GMO labels, as $85.3 \%$ of participants state that they see these labels in supermarkets in the United States. Furthermore, 79.4\% of these participants state that their beliefs regarding GMOs and the environment affect their purchasing decisions at least all of the time or sometimes. It should also be noted that the participants who have negative attitudes toward GMOs and their environmental impact tend to be proponents of GMO labeling policies [21].

These findings are consistent with the previous studies that assert that consumers tend to have negative attitudes toward GMO food production and its impact on the environment. As previously discussed, consumers have a low acceptance level regarding GMOs regarding their safety and impact on the environment [13]. However, data from this study conflicts with the previous studies that show that there is a lack of awareness surrounding the term GMO among consumers. The majority (98.5\%) of participants within this study have heard of the term 'GMO' which may be due to the population's educational level as the survey was 
administered on the university campus listserv. Conversely, another university, in New Jersey, Rutgers University, study dealt with a population very unfamiliar with the term GMO, with approximately $54 \%$ of participants admitting to knowing little to nothing about the term [7].

The results and the previous findings suggest that beliefs regarding how GM food production impacts the environment have the potential to influence consumers' preference and ultimately purchasing behaviors and they prefer to see labels to indicate the food production method. An increased consumer demand for GMO labels has the power to impact labeling policies and even the types of foods that food companies decide to produce. The powerful influence of consumers' beliefs highlights the importance of relaying accurate information about GMOs to the public. The findings pose the question of where consumers are getting the idea that certain products are more desirable, valuable, safer or environmentally friendly than others? It is evident that non-GMO labels have a powerful impact not only on consumers' attitudes and beliefs but also on their purchasing decisions. A systematic review from the American Journal of Agricultural Economics discusses the confusion surrounding the new abundance of information available to consumers via labels. The review attributes consumers' difficulty understanding labels to three things: (1) messages on labels are often complex, (2) there are a variety of labels on the market that have similar meanings and (3) the risks and benefits of certain labels are misrepresented and therefore misinterpreted. Certain products are being portrayed as superior due to their labels, yet consumers cannot determine whether or not this desirability is actually of any value [22]. Another factor to be considered is that consumers may not fully understand the meaning of certain labels. The additional information may sometimes make it even more challenging for them to comprehend the validity of certain claims. This suggests that consumers may not be consumers freely or accurately exercising their beliefs when purchasing non-GMO products since they may not be able to fully understand the information on the food labels.

\section{CONCLUSIONS}

There are several methods of agricultural practices to produce food in the United States. Consumers are not fully aware of these practices, and hence, their food preferences and purchasing choices are influenced by many factors. It is important to educate consumers about the food production systems and their possible impact on the environment. An important conclusion to be drawn from this study is that despite the lack of general knowledge available regarding the impact that GMOs have on the environment, consumers have strong opinions about how food production systems impact the environment. There is, therefore, a need for more consumer education regarding the safety of GM food production in regard to the environment. If consumers were more knowledgeable about the risks and benefits surrounding purchasing foods with GM-containing ingredients, then they would be able to develop more educated opinions and attitudes about them. More consumer education would allow consumers to decipher labels more accurately and make purchasing decisions that accurately reflect their beliefs. Future research regarding the risks and benefits of GMO food production is also needed so that credible and reliable information may be conveyed to consumers. This would ultimately allow consumers to freely exercise their beliefs while making informed decisions. The growing popularity of non-GMO products is expected to drive growth of organic food around the globe to $\$ 320$ billion by 2025 as people become more aware of the environmental impact of other food production systems [23]. This rapid growth places further emphasis on the need to increase knowledge and awareness of the impact that GM food production has on the environment.

The main limitation of this study is that the sample population was small, largely white, female and from northern New Jersey [21]. Therefore, the results cannot be generalized to 
the entire United States population. Further research in this area using a more diverse population using a larger sample size would provide more insight to this issue. There is also the risk of survey bias within this study, as participants may have responded in ways that make their purchasing decisions appear more altruistic than they actually are.

\section{VITAE}

Shahla Wunderlich is a Professor of Nutrition and Food Science at Montclair State University.

She studies the full spectrum of nutritional needs - for mothers and children and older adults. Her scholarly interests include nutrition assessments, global food studies and, most recently, food production systems and their environmental impact. She served as an editor and reviewer of nutrition textbooks. Dr. Wunderlich received her Ph.D. from the Massachusetts Institute of Technology (MIT) in Nutritional Biochemistry and Metabolism. She is a Registered Dietitian (RD) and Certified Nutrition Specialist. She has received many awards, including the Outstanding Dietetic Educator Award and the Montclair State University Outstanding Faculty Award.

Marielle Smoller is a Nutrition and Food Science graduate student at Montclair State University. She is also a Registered Dietitian (RD) and completed both her undergraduate coursework and Dietetic Internship at the University of Delaware. She has experience in weight management counseling in the outpatient setting. As a graduate assistant at Montclair, Marielle collaborates with the faculty members in the Department of Nutrition and Food Studies on a variety of research studies such as research on consumer knowledge and attitudes toward GMO products.

\section{REFERENCES}

[1] Harvard University Web Publishing, What is the Food Supply Chain? [PDF document], Meant4Teachers: Toronto, available at http://meant4teachers.com/wpcontent/ uploads/2014/02/What-is-the-Food-Supply-Chain.pdf (accessed 16 November 2017).

[2] Govindan, K., Sustainable consumption and production in the food supply chain: a conceptual framework. International Journal of Production Economics [serial on the Internet], available at http://doi:10.1016/j.ijpe.2017.03.003, 2017 (accessed 16 November 2017).

[3] Vecchione, M., Feldman, C. \& Wunderlich, S., Consumer knowledge and attitudes about genetically modified food products and labelling policy. International Journal of Food Sciences \& Nutrition [serial on the Internet], 66(3), pp. 329-335, 2015, available at SPORTDiscus with Full Text. DOI: 10.3109/09637486.2014.986072.

[4] León-Bravo, V., Caniato, F., Caridi, M. \& Johnsen, T., Collaboration for sustainability in the food supply chain: a multi-stage study in Italy. Sustainability [Internet], 9(7), p. 1253, available at https://doi.org/10.3390/su9071253, 2017 (accessed 16 November 2017).

[5] Kini, V., Coca-Cola India Sustainability Report 2014 [Internet], Coca-Cola India Pvt. Ltd: Haryana, 100 p, available at https://www.coca-colaindia.com/stories/sustainability/ downloads/sustainability-report-2014, 2014.

[6] U.S. Department of Agriculture [Internet], U.S. Department of Agriculture: Washington, DC. Biotechnology FAQs [about 4 screens], available at https://www.usda.gov/ topics/biotechnology/biotechnology-frequently-asked-questions-faqs, 2017 (accessed 16 November 2017).

[7] Hallman, W.K., Cuite, C.L. \& Morin, X.K., Public Perceptions of Labeling Genetically Modified Foods (Working Paper No. 2013-1) [Internet], available at http://humeco.rutgers.edu/documents_PDF/news/GMlabelingperceptions.pdf, 2013 (accessed 16 November 2017). 
[8] Non GMO Project [Internet], The Non-GMO Project: Bellingham, WA, Product Verification, available at https://www.nongmoproject.org/product-verification/, 2016 (accessed 16 November 2017).

[9] Blake, P., ABC News [Internet], ABC News Internet Ventures: New York, NY, Obama Signs Bill Mandating GMO Labeling, 29 July 2016 [about 1 screen], available at http:// abcnews.go.com/US/obama-signs-bill-mandating- gmolabeling/story?id=41004057, 2016 (accessed 16 November 2017).

[10] United States Department of Agriculture Agricultural Marketing Service [Internet], U.S. Department of Agriculture: Washington, DC, Organic Labeling, available at https://www.ams.usda.gov/rules-regulations/organic/labeling, 2016 (accessed 16 November 2017).

[11] United States Department of Agriculture (Report) Office of Communication, [Internet]. United States Department of Agriculture: Washington, DC, USDA Coexistence Factsheet: Conventional Farming, available at https://www.usda.gov/sites/default/files/ documents/coexistence-conventional-farming-factsheet.pdf, 2015 (accessed 16 November 2017).

[12] Sax, J. \& Doran, N., Food labeling and Consumer Associations with Health, Safety, and Environment. Journal of Law, Medicine \& Ethics [serial on the Internet], 44(4), pp. 630-638, available at https://doi.org/10.1177/1073110516684805, 2016 (accessed 16 November 2017).

[13] Aleksejeva, I., An empirical study of Latvian consumers' attitudes and perceptions towards genetically modified organisms. European Integration Studies [serial on the Internet], 10(10), pp. 157-168, available at http://eis.ktu.lt/index.php/EIS/article/ viewFile/14624/8518, 2016 (accessed 16 November 2017). DOI: http://dx.doi. org/10.5755/j01.eis.0.10.14628.

[14] Turker, T., Kocak, N., Aydin, I., İstanbulluoğlu, H., Yildiran, N., Kilic, S., et al., Determination of knowledge, attitude, behavior about genetically modified organisms in nursing school students. Gulhane Medical Journal [serial on the Internet], 55(4), pp. 297-304, available at http://gulhanemedj.org/abstract.php?id=776, 2013 (accessed 16 November 2017).

[15] Brown, J. \& Kuzma, J., Hungry for information: public attitudes toward food nanotechnology and labeling. Review of Policy Research [serial on the Internet], (5), p. 512, available at https://onlinelibrary.wiley.com/doi/abs/10.1111/ropr.12035, 2013 (accessed 16 November 2017).

[16] Wunderlich, S. \& Gatto, K.A. Consumer perception of genetically modified organisms and sources of information. Advances in Nutrition [Internet], 6(6), pp. 842-851, available at https://doi.org/10.3945/an.115.008870, 2015 (accessed 16 November 2017)

[17] National Academies of Sciences, Engineering, and Medicine, Division on Earth and Life Studies; Board on Agriculture and Natural Resources; Committee on Genetically Engineered Crops: Past Experience and Future Prospects, National Academies of Sciences, Engineering, and Medicine: Washington, DC, 606 p, available at https://www.nap.edu/ initiative/committee-on-genetically-engineered-crops-past-experience-and-future-prospects, 2016 (accessed 16 November 2017).

[18] Wunderlich, S., Gatto, K. \& Smoller, M., Consumer knowledge about food production systems and their purchasing behavior. Environment, Development, and Sustainability [Internet], pp. 1-11, available at https://doi.org/10.1007/s10668-017-0021-y, 2016 (accessed 16 November 2017). 
[19] Meier, M., Stoessel, F., Jungbluth, N., Juraske, R., Schader, C. \& Stolze, M., Review: environmental impacts of organic and conventional agricultural products - are the differences captured by life cycle assessment?. Journal of Environmental Management [serial on the Internet], pp. 193-208, available at https://www.ncbi.nlm.nih.gov/pubmed/25463583, 2015 (accessed 16 November 2017).

[20] Tsatsakis, A.. Nawaz, M., Kouretas, D., Balias, G., Savolainen, K., Chung, G., et al., Environmental impacts of genetically modified plants: a review. Environmental Research [serial on the Internet], 156, pp. 818-833, available at https://www.ncbi.nlm. nih.gov/pubmed/28347490, 2017 (accessed 16 November 2017).

[21] Wunderlich, S. \& Smoller, M., Food supply chain in the United States: potential environmental impact. WIT Transactions on Ecology and the Environment, Vol. 215, WIT Press: Southampton, ISSN 1743-3541, 2018.

[22] Bonroy, O. \& Constantatos, C., The economics of labels: how their introduction affects the functioning of markets and welfare of all participants. American Journal of Agricultural Economics [Internet], 97(1), pp. 239-259, available at http://doi.10.1093/ajae/ aau088, 2015 (accessed 16 November 2017).

[23] Zechmeister, M., New Hope Network [Internet], New Hope Network: Boulder, CO Prediction: Organic foods and beverages market to reach $\$ 320$ billion by 2025 , available at https://www.newhope.com/news/prediction-organic-foods-and-beverages-market-reach320-billion-2025, 2017 (accessed 16 November 2017). 